\section{Promoção da saúde da mulher indígena: contribuição da etnografia das práticas de autoatenção entre os Munduruku do Estado do Amazonas, Brasil}

\author{
Health promotion with indigenous women: \\ the contribution of ethnography on self-care \\ practices among the Munduruku people \\ in the Amazonas State, Brazil
}

Promoción de la salud de la mujer indígena: contribución de la etnografía de prácticas de autoatención entre los Munduruku del estado de Amazonas, Brasil

\section{Resumo}

A longevidade, a saúde e o bem-estar coletivo e individual figuram entre as expectativas socialmente compartilhadas pelos Munduruku que habitam a Terra Indígena Kwatá-Laranjal, Amazonas, Brasil. A condução da vida diária, em um cosmo pleno de seres, é cercada de perigos que ameaçam essas expectativas, cujas agências podem resultar em doença e morte. A partir de etnografia, conduzida por meio da observação participante e narrativas, analisamos as práticas de autoatenção voltadas à construção do corpo da mulher Munduruku, valorizando a perspectiva e o papel ativo das pessoas "leigas" nesse processo. Essas práticas iniciam-se na gestação e estendem-se ao longo da vida, em um processo contínuo de construção do corpo, manutenção da saúde e aquisição de habilidades, marcado pela interação entre pessoas de diferentes idades. O foco das práticas de atenção Munduruku não é o corpo no sentido dado pelo paradigma biomédico, mas a participação deste, como pessoa, nas relações sociais e cosmológicas, por meio de experiências que articulam corpo, saúde e ambiente. A perspectiva Munduruku sobre esse processo apresenta diferenças radicais em relação ao individualismo moderno e à noção biomédica de corpo excessivamente reducionista. A compreensão da perspectiva indígena contribui para promover melhorias na qualidade da atenção diferenciada, conforme preconizado pela Política Nacional de Atenção à Saúde dos Povos Indígenas.

Saúde de Populações Indígenas; Índios Sul-Americanos; Antropologia Médica; Saúde da Mulher
Raquel Paiva Dias-Scopel 1

Daniel Scopel 2

doi: 10.1590/0102-311X00085918

\author{
Correspondência \\ R. P. Dias-Scopel \\ Fiocruz Mato Grosso do Sul. \\ Rua Gabriel Abrão 92, Campo Grande, MS \\ 79074-460, Brasil. \\ raquel.scopel@gmail.com \\ 1 Fiocruz Mato Grosso do Sul, Campo Grande, Brasil. \\ 2 INCT Brasil Plural, Campo Grande, Brasil.
}




\section{Introdução}

Segundo os Munduruku, é preciso estar atento às interdições e prescrições relativas à menstruação, dado que o sangue menstrual é capaz de atrair bichos do fundo. Evitar relações com os bichos do fundo é uma forma de prevenir infortúnios, doenças e morte. Ao mesmo tempo, cumprir interdições e prescrições relativas à menstruação é uma forma de desenvolver habilidades e virtudes valorizadas socialmente como atributos de uma pessoa plena e saudável, capaz de participar das redes de apoio mútuo estabelecidas em torno dos laços do parentesco.

Segundo Alan Young 1, as práticas relativas aos processos de saúde, doença e atenção-prevenção implicam a construção social e ontológica da realidade, compreendendo o modo particular como cada sociedade ou cultura promove a mediação entre os aspectos materiais e simbólicos da experiência, na medida em que evidenciam expectativas sobre o papel social de atores, a avaliação contínua das experiências vividas e da eficácia dos saberes.

Para Menéndez 2 (p. 48, grifo nosso), stricto sensu, a autoatenção compreende “...representações e práticas que a população utiliza no nível do sujeito e do grupo social para diagnosticar, explicar, atender, controlar, aliviar, aguentar, curar, solucionar ou prevenir os processos que afetam sua saúde em termos reais ou imaginários, sem a intervenção direta, central e intencional de curadores profissionais”. Lato sensu, autoatenção abrange atividades compreendidas pelos próprios sujeitos como ações que contribuem para o processo da reprodução biossocial, por exemplo, saberes relacionados à "preparação e distribuição de alimentos, da higiene do lar, do entorno e do corpo, a obtenção e uso de água etc.” 2 (p. 48).

Investigar os saberes de autoatenção é importante, tanto para compreender a forma como os conjuntos sociais vivenciam processos de saúde, doença e atenção-prevenção, como para sensibilizar aqueles que, profissionalmente, trabalham na atenção à saúde indígena e que almejam maior eficiência e eficácia das próprias práticas 2,3,4,5,6.

A autoatenção é um processo constante, estruturante e presente em todos os microgrupos sociais, fato frequentemente negado ou ignorado por atores sociais que reproduzem o modelo médico hegemônico 2. Segundo Menéndez, a definição de modelo médico hegemônico é heurística e caracteriza-se prioritariamente por orientação biológica, organização burocrática, individualismo, relações médico-pacientes assimétricas, legitimação jurídico-acadêmica, profissionalização formal e identificação com a racionalidade científica 2 .

Os processos de saúde, doença e atenção-prevenção têm sido privilegiados pela antropologia da saúde para compreender dinâmicas socioculturais em contextos locais, caracterizados pelo pluralismo médico e assimetria de poder 4,5. As diversas formas de atenção e os diferentes pontos de vista de atores sociais implicam a emergência de relações de hegemonia/subalternidade com efeitos que transcendem o contexto local 2,3. Uma das contribuições da antropologia da saúde ao campo da saúde indígena tem sido fornecer subsídios à formulação de políticas públicas, pela crítica ao modelo médico hegemônico, pelo reconhecimento das especificidades socioculturais locais e pela etnografia dos processos de saúde, doença e atenção-prevenção 2,3,4,5,6.

$\mathrm{Na}$ América Latina, entre as populações indígenas, a autoatenção desenvolve-se em contexto de pluralidade médica, ou seja, um contexto complexo, cultural e politicamente diversificado de formas de atenção tradicionais, populares, religiosas e biomédicas ${ }^{2}$. Em tal contexto, é inegável a crescente participação desta última forma como paradigmática do modelo médico hegemônico promovido pelos Estados Nacionais por meio de políticas públicas. Da mesma forma, é preciso esclarecer que o modelo médico hegemônico não se tornou um substituto das demais formas que, com frequência, são articuladas no processo de autoatenção 4.

Algumas etnografias sobre saúde indígena 7,8 têm apontado que a pluralidade médica entre populações indígenas tende a ser percebida pelos atores sociais como um campo polarizado, e o papel ativo das pessoas leigas nos processos de saúde, doença e atenção-prevenção por meio da autoatenção é, com frequência, negado ou ignorado 2 .

Neste artigo, apresenta-se uma análise etnográfica das práticas relativas à menstruação entre os Munduruku do Amazonas, Brasil, para enfatizar a dinâmica pragmática, social e ontológica do processo de autoatenção. Ao enfatizar as práticas indígenas, evidencia-se a necessidade de, cada vez mais, executar ações de atenção e aprimorar políticas públicas com maior sensibilidade às especificidades socioculturais, capazes de promover a saúde e a qualidade de vida, em articulação com os saberes indígenas. 


\section{Metodologia e contexto da pesquisa}

O povo Munduruku compreende cerca de 10 mil pessoas que habitam terras indígenas nos estados do Mato Grosso, Pará e Amazonas 9. Os dados etnográficos deste artigo foram obtidos por meio de observação participante, coleta de narrativas e entrevistas junto aos Munduruku do Estado do Amazonas que habitam a Terra Indígena Kwatá-Laranjal (TIKL). Eles representam a segunda maior concentração populacional da etnia (2.500 habitantes). No século XVII, registra-se a inserção dos Munduruku no contexto regional como povo guerreiro e comerciante. Desde o século XVIII, eles têm mantido relações interétnicas frequentes com europeus, caboclos, ribeirinhos e com demais etnias indígenas, como os Mura e os Sateré 9,10,11,12.

Na TIKL, todos falam português e, por esse motivo, os pesquisadores não necessitaram de tradutores para realizar a pesquisa. A língua Munduruku (tronco Tupi) encontra-se em processo de revitalização na TIKL, porém não é utilizada no cotidiano 10. Segundo Amoroso 11, entre os povos indígenas do Baixo Rio Madeira, a utilização da língua portuguesa apresenta mudanças semânticas e variações lexicais. Termos em português possuem sentidos ampliados e diferenciados. Por esse motivo, neste artigo, algumas palavras em português são escritas em itálico.

A observação participante foi conduzida em diversas viagens à TIKL, totalizando cerca de um ano de trabalho de campo. Os autores realizaram três estadas prolongadas em janeiro e fevereiro de 2009, agosto a dezembro de 2010 e de março a junho de 2011, e mais quatro meses distribuídos ao longo de 2017. Para realizar a observação participante, estabelecemos residência entre famílias nas aldeias Kwatá, Niterói e Jacaré e, a partir desses locais, realizamos diversas viagens a outras aldeias próximas.

Foi possível coabitar com os interlocutores em todos os momentos da pesquisa. Assim, desde o início do trabalho de campo, os pesquisadores compartilharam o espaço doméstico, incluindo-se no cotidiano de algumas famílias elementares. O termo família elementar, analiticamente, difere do conceito de família nuclear, conforme argumenta Mellati 13, referindo-se ao grupo que compartilha o espaço doméstico e que pode ou não estar ligado por laços de consanguinidade. Uma família elementar Munduruku é composta de pessoas, frequentemente o casal e os filhos, mas admite outras configurações, inclusive situacionais e transitórias, de pessoas que compartilham a mesma roça, a mesma casa, a alimentação diária e que se ajudam mutuamente nas tarefas relacionadas à manutenção do núcleo doméstico como limpeza, capina, fabricação de farinha, bem como buscar água e prestar auxílio mútuo em casos de doença.

A morfologia social das aldeias Munduruku está arranjada em torno do que Mellati 13 designa de segmentos residenciais, coabitados por pessoas com algum grau de parentesco, agrupando um conjunto de famílias elementares. Assim, os segmentos residenciais, com frequência, coincidem com o espaço habitado pela família extensa, mas isso não é regra. É através da participação e do engajamento nas atividades de produção, circulação e consumo de alimentos, troca de apoio mútuo e de serviços e, especialmente relevante para este artigo, por meio da participação no processo de autoatenção que se consolidam, se mantêm e se conformam relações que possibilitam a continuidade das famílias extensas, à semelhança do que acontece em outros grupos indígenas 14,15,16,17.

Entre os Munduruku, atualmente, o contexto é de pluralidade médica, ou seja, com muita frequência, os itinerários terapêuticos incluem consultas a praticantes de formas xamânicas de atenção, mas também há acesso à atenção biomédica 9,18. A atenção biomédica é ofertada por meio do Subsistema de Atenção à Saúde Indígena (SASI) e, nas aldeias, a atenção primária é desenvolvida pelas Equipes Multidisciplinares de Saúde Indígena (EMSI). A experiência dos indígenas com serviços biomédicos ocorre desde a infância por meio de consultas, rotinas de pesagem, avaliação nutricional, campanhas de vacinação, rotinas de pré-natal etc. 18,19 .

\section{A experiência da menarca}

Ao analisar a memória social das experiências de autoatenção à menarca, é possível sublinhar expectativas relacionadas ao ciclo de vida das mulheres Munduruku. Essas expectativas evocam a noção de que o corpo é, sobretudo, um produto social constituído por meio de atividades cotidianas e rituais, como práticas de autoatenção à puberdade, menarca, gestação, parto e pós-parto. Realizam-se ativida- 
des que vinculam o corpo, a coletividade e o cosmo ao ambiente que investigam e conhecem profundamente, já que ali vivem e circulam. As exortações das mulheres mais velhas para o cumprimento das práticas de autoatenção à menarca e à menstruação têm como objetivo explícito a produção do corpo da mulher em conformidade com habilidades e disposições morais que correspondem às expectativas da vida adulta plena com saúde, capaz de responder às responsabilidades sociais e atender, prevenir, evitar, curar ou combater os perigos advindos da relação com os demais seres do cosmo, tema que desenvolveremos adiante.

A noção de que o corpo é um produto social e, entre populações indígenas, vivenciado como um artefato culturalmente fabricado é amplamente discutida pela literatura etnológica 16. Entre os Munduruku, na menarca, esse processo de fabricação do corpo e da pessoa inclui reclusão, defumações e banhos terapêuticos. Nos ciclos menstruais posteriores, observamos que as mulheres não ficam reclusas em casa, mas evitam banhar-se ou realizar qualquer atividade na beira do rio ou na cacimba. Além disso, as mulheres também realizam dietas alimentares e ingestão de chás durante a menstruação com diversos propósitos, como fortificar o corpo, minimizar o tempo de duração e o fluxo do sangue, mas, principalmente, para controlar a concepção.

As experiências evocadas nas narrativas motivam a participação das meninas nas atividades de autoatenção, de tal forma que o processo se reveste menos de uma imposição coercitiva e ritualizada do que de um engajamento voluntário nas redes de apoio mútuo que caracteriza o processo de autoatenção entre as mulheres Munduruku. As atividades cotidianas e, principalmente, as rodas de conversas, em que participam mulheres de diversas idades, cercadas por filhas, netas e sobrinhas, são momentos privilegiados para a troca de experiências e narrativas, nas quais as preocupações relativas às práticas de autoatenção são tema frequente.

Tornar-se uma mulher adulta "esperta" e com "disposição" faz parte das motivações para cumprir o resguardo da menarca. Entre as práticas de autoatenção à menarca, Lúcia (40 anos) citou a reclusão no interior da casa e não "brechar" (espiar por entre as frestas da casa). Lembrou também que sua mãe e avó fizeram "defumações" e "banhos com plantas cheirosas" ao longo de três dias após findar o sangramento. Ceci (92 anos) aprendeu com a mãe que devia cumprir o resguardo com "disposição", isto é, ficar na "rede, tecendo alguma coisa, faz alguma atividade, na rede, pra ti ser uma mulher esperta". A mulher com disposição ou esperta é aquela que age com vivacidade, de modo intencional e espontâneo, que tem iniciativa e desenvolve as atividades cotidianas com zelo e diligência, especialmente com relação à produção e circulação dos alimentos, nas trocas de serviços, nos apoios mútuos, no cuidado com os filhos e parentes. Para os Munduruku, disposição e esperteza indicam tanto um estatuto de pessoa plena como também de pessoa saudável, cujos significados se associam à autonomia e iniciativa na condução da vida diária e das relações sociais.

O ânimo e o estado de espírito da menina, ao cumprir o resguardo da menarca, contribuem para formar o caráter da mulher Munduruku. Ao cuidar do corpo recluso, as mulheres Munduruku têm por objetivo o ideal da pessoa saudável que, por esse motivo, não representa ameaça para as pessoas próximas. A atitude contrária, para os Munduruku, é representada pela "mulher mufina", que não segue as prescrições e restrições associadas à menstruação, pois a falta com a correta autoatenção pode prejudicar outras pessoas, ainda que sem intenção.

O resguardo da menarca e da menstruação exemplifica modos de ação intencional sobre o corpo e a pessoa, com foco na construção e manutenção de virtudes socialmente valorizadas da mulher Munduruku. Conforme sintetiza Araci, "mulher tem que se resguardar para ter saúde quando for mais velha" ou, ainda, conforme outras mulheres advertem, para não se tornarem "filhentas", "andarilhas" ou "preguiçosas", termos depreciativos, segundo os Munduruku.

\section{A autoatenção à menstruação}

As práticas de autoatenção à menstruação evidenciam rico exemplo do cumprimento de protocolos de aproximação e afastamento entre os Munduruku e os demais seres que habitam o cosmo, na condução da vida diária em busca de bem-estar e manutenção da saúde.

Iara (35 anos), uma de nossas anfitriãs, contava com a ajuda do marido e dos filhos meninos para banhar-se no interior da casa durante o período menstrual. Eles carregavam baldes de água do rio até 
o quarto todos os dias durante o resguardo da menstruação. O resguardo da menstruação durava até três a quatro dias após o fim do sangramento, isto é, não coincidia com o final do fluxo fisiológico do sangue, mas com a perspectiva cosmológica Munduruku acerca da agência dos seres e das relações que devem ser evitadas. Durante os resguardos da menstruação, Iara ingeriu diferentes tipos de chás, ao longo do dia, e não descia para o rio ou cacimba para lavar roupas ou louças. Ela restringia seu espaço de circulação ao entorno da casa, evitava frequentar a roça, a casa de farinha e, até mesmo, circular no espaço do segmento residencial. A restrição dos espaços de circulação era evocada como prática adequada, principalmente pelas mulheres mais velhas.

Durante o trabalho de campo, ficou evidente que nossas anfitriãs tinham expectativas quanto ao ciclo menstrual da antropóloga, questionando-a frequentemente. A preocupação das mulheres com a menstruação das outras mulheres da família pode ser entendida não como um rígido controle sobre os corpos, mas como um tênue cuidado mútuo. Conforme explicou Ceci, nossa anfitriã, na expectativa de instruir e alertar a pesquisadora, os perigos do descumprimento das restrições e prescrições associadas ao resguardo da menstruação não afetam apenas a vida das mulheres menstruadas, mas podiam recair sobre qualquer pessoa, principalmente os membros da família extensa e, especialmente, as crianças.

Ceci narrou o caso de uma nora, Sandi, que "endoidou, teve assombração de bicho do fundo", porque o boto se sentiu atraído por ela e intencionava levá-la para o Encante, a cidade submersa dos "botos encantados". A causa do sofrimento, mal-estar, dor de cabeça, falta de apetite, prostração, perda da consciência e quase morte de Sandi foi devido a um ato praticado pela mãe de Sandi. Sem saber que o sangue menstrual atraía os botos porque, para eles, "cheira como ananás", a mãe de Sandi "jogou os panos sujos no rio" durante uma viagem à aldeia Malocão. Sandi e sua mãe não eram Munduruku e desconheciam os protocolos que garantem saúde e bem-estar relativos ao sangue menstrual. Como não havia melhora de Sandi, recorreram a uma curadora pajé-sacaca. Curadores pajé-sacaca têm habilidade de transitar entre este mundo e o mundo subaquático e também conhecem os pontos fracos dos "espíritos malignos".

Ceci contou que Nair, a pajé-sacaca, fizera defumações e benzimentos por toda uma noite, para que o "bicho" abandonasse Sandi e desistisse de levar a "sombra" dela para o Encante. A curadora receitou "banhos de planta cheirosa", para serem feitos durante três dias, e recomendou que Sandi não voltasse mais à aldeia Malocão.

O boto maligno intencionava levar a sombra de Sandi para o fundo do rio, para morar no "Encante", onde "viveria na fartura" entre os botos que, lá, têm a forma humana e vivem como "gente", possuem família, trabalham, festejam etc. Entretanto, a passagem para o Encante implica a ruptura com este mundo, ou seja, a morte. A convivência prolongada com os bichos do fundo afeta a consciência e o corpo, à semelhança do que foi registrado sobre a relação entre humanos e não humanos entre os Matsigenka, no Peru 17.

Diferentes etnografias apontam que a noção de sangue entre os povos indígenas emerge como símbolo que articula o corpo em suas dimensões biológica, social e cosmológica 20,21,22,23,24,25. Segundo os Munduruku, o sangue menstrual é capaz de gerar vida e morte. Possui característica volátil e atrai seres que habitam espaços específicos no cosmo (rio, igarapés ou olho d’água de cacimba), em particular, botos e cobras encantadas, com os quais as relações sociais frequentemente resultam em doenças, infortúnios e mortes, como "mau olhado de boto", "ser levado para o Encante", "assombro de bicho", "filho de bicho" 24,25,26. O odor do sangue menstrual tem, segundo os Munduruku, a capacidade de se propagar no ar e de demarcar o "rastro" da mulher menstruada. Esse odor do sangue menstrual, de acordo com Ceci, "é pitiú para gente, mas para eles é que nem ananás". Pitiú é uma palavra de uso corrente para designar cheiro forte e desagradável, associado ao cheiro da carne de peixe podre. Para os Munduruku, o ato de aceitar a comida ofertada pelos bichos do fundo, botos e encantados ou manter relações sexuais com eles desencadeia infortúnios, doenças e morte, à semelhança do que se registra para outros grupos ribeirinhos e indígenas amazônicos 27,28,29,30,31,32.

As crianças que circulam sobre o rastro da mulher menstruada podem sofrer ataques dos encantados e serem raptadas por eles. $\mathrm{O}$ simples contato fortuito pode ser perigoso. O mau olhado de bicho, por exemplo, resulta em medo, tremores no corpo, febre, visões e sonhos com comidas e relações sexuais. Nesses casos, somente o pajé pode curar o enfermo, por meio de rezas e da prescrição de banhos. $\mathrm{O}$ tratamento é longo e pode incluir "de três a sete rezas" e "banhos com plantas cheirosas toda sexta-feira", além de prescrições a serem seguidas para a vida toda como, por exemplo, evitar passar por determinados lugares e banhar-se em certos horários. 
Outra consequência da quebra do resguardo da menstruação é a gravidez de bicho. Os Munduruku compartilham noções sobre concepção, fisiologia e anatomia que divergem daquelas praticadas pela biomedicina 33. A concepção, segundo os Munduruku, resulta da união do sangue com o sêmen. Assim, o sangue menstrual é tanto fonte de vida que contribui para consolidar a união e maturidade de um casal por meio da geração de filhos, crianças, como é também fonte de perigo. Da relação sexual entre uma mulher menstruada e um bicho, realizada em sonhos, podem nascer seres híbridos com "corpo de cobra e cabeça de criança" ou "corpo de gente e tronco e cabeça de boto". Os desfechos desse infortúnio podem ser os seguintes: aborto, morte da criança (o mais comum é o "filho de bicho" nascer morto ou ser "levado para o fundo" por seu pai encantado) e morte da mulher.

Os Munduruku evocam, com frequência, experiências pessoais ou de pessoas próximas que adoeceram ou faleceram por conta da quebra das interdições e prescrições relativas ao resguardo da menstruação. Nesse sentido, as práticas de autoatenção relativas à menstruação são realizadas pelos Munduruku com a intenção pragmática de manter a saúde da mulher menstruada e dos demais membros do grupo, especialmente das crianças. A experiência do resguardo pressupõe a apreensão de um saber cosmológico que é incorporado por meio de práticas de autoatenção à menstruação.

A experiência da realização das práticas de autoatenção à menstruação não se constitui como uma imposição social ou um aprisionamento, mas, ao contrário, é percebida como um saber valorizado, como uma conduta ideal que repercutirá em saúde e longevidade para a mulher adulta. Não seguir o resguardo da menstruação implica romper com os protocolos que orientam as relações adequadas de afastamento com os seres perigosos e letais que habitam o cosmo.

\section{Habilidades sociais e agência cosmológica}

Entre os Munduruku, as práticas de autoatenção evidenciam uma noção de corpo integrada que não dissocia a materialidade do corpo individual da construção das habilidades sociais e da agência cosmológica. A formação do corpo e do caráter da pessoa inicia-se ainda na gestação e, ao longo da vida, um conjunto de atividades tende a ser realizado de maneira intencional, com o objetivo de alcançar o status socialmente desejado consoante as expectativas de uma vida plena com saúde. Corpo e pessoa, entre os Munduruku, são produtos da ação coletiva e intencional, semelhante ao que foi registrado entre outros grupos indígenas 16,17,34,35,36. Não somente a pessoa, mas o próprio corpo é compreendido como produto da ação coletiva, na medida em que se requer a intervenção contínua de pessoas mais velhas na sua constituição, crescimento, maturação, bem como na manutenção da saúde através das práticas de autoatenção.

Pais e mães Munduruku cumprem restrições alimentares e comportamentais durante a gestação, com objetivo de controlar a formação do corpo e do caráter da criança, para evitar gerar uma criança com dificuldades para engatinhar, andar ou boca aberta. Evita-se, por exemplo, ingerir carne de macaco-prego, porque a criança teria tendência a se expor a situações de risco, dado seu comportamento descuidado ou desobediente nas brincadeiras e atividades diárias, como nadar, subir em árvore etc. Evita-se comer um tipo de peixe sem espinha, porque a criança "nasceria mole", sem forças para sustentar a cabeça, para engatinhar e andar. Não se deve negar o pedido de uma gestante por comida, nem ela deve calar-se diante do desejo por algum alimento, porque a criança se tornaria boca aberta. A criança boca aberta é aquela que não tem iniciativa e é apática. Diz-se que uma criança boca aberta se tornaria um adulto pouco colaborativo, sem iniciativa para trabalhar, especialmente nas atividades coletivas de produção de alimentos. Isso não é desejável, porque impacta as atividades de subsistência e as relações de produção e manutenção dos laços afetivos e de colaboração entre as famílias elementares.

Para os Munduruku, o bebê, desde a gestação, possui agência sobre o mundo social, na medida em que pode abalar o pai, isto é, roubar-lhe a força e a gordura, que juntas conferem vitalidade ao homem. O bebê no ventre materno é compreendido como ser que interage e participa de um circuito de trocas de substâncias corporais 24 . Esse processo não se restringe aos pais e, em menor medida, é suscetível aos que se mantêm próximos. Se a grávida toma ao colo outra criança, por exemplo, o bebê em gestação pode "roubar os cabelos da criança" para formar o próprio corpo.

A pessoa Munduruku se constitui por meio da participação em uma rede de relações sociais que se inicia no âmbito doméstico, onde as relações entre pessoas de diferentes idades ocupam um papel 
de destaque, principalmente nas práticas de autoatenção. O status de pessoa Munduruku e do corpo saudável materializa-se no domínio de certas habilidades exercidas com autonomia e disposição, garantindo força e bem-estar para o indivíduo e para a coletividade. Entre os Munduruku, o domínio dessas habilidades é uma conquista física e social, assim como descrito entre outros povos 16,17,21,36.

A saúde dos bebês Munduruku depende do cumprimento das prescrições e proibições comportamentais a que se submetem o pai e a mãe, muito intensas no período de "resguardo do parto", e que continuam durante os primeiros anos. No resguardo do pós-parto, a mãe mantém-se reclusa com rígida dieta, e o pai afasta-se dos trabalhos usuais, assumindo tarefas domésticas para evitar danos ao corpo do bebê. O pai evita realizar inúmeras tarefas, como, por exemplo, fazer movimentos bruscos ou atar nós. Mais tarde, conforme cresce o bebê, por exemplo, o pai não pode agradar a criança quando chega do trabalho com fome, pois isso pode causar-lhe quebranto, uma enfermidade caracterizada pela diarreia, mas que não se confunde com o diagnóstico biomédico, devendo ser tratado com rezas. Conforme crescem, os bebês também recebem constantes massagens e manipulações, no intuito de moldar seus corpos, conferindo forma aos músculos e ossos.

As crianças Munduruku participam desde muito cedo nas atividades diárias, pois estão sempre acompanhando os adultos. Espera-se, inclusive, que contribuam ativamente na produção dos meios de subsistência (roça, pesca, caça), na medida em que conquistam as habilidades necessárias. $\mathrm{O}$ ajuri ou mutirão, por exemplo, é uma etapa da produção da mandioca feita de forma coletiva, envolvendo diferentes pessoas da família extensa. Observa-se que, no plantio, crianças, mulheres, homens e idosos dividem as tarefas de modo complementar. Sugerimos que o envolvimento e a participação no mutirão entre os Munduruku são um momento privilegiado para as crianças desenvolverem habilidades físicas, sociais e morais, semelhante aos modos de transmissão de conhecimentos registrados entre outros povos indígenas $14,15,16$.

As crianças, meninos e meninas participam ativamente do plantio, distribuindo manivas (pedaço do caule) nos buracos cavados pelos homens adultos. A habilidade socialmente valorizada (saber plantar e colaborar em atividades) é construída pela participação ativa sob a vigilância e orientação das mulheres adultas, que cobrem as covas com terra. A participação das famílias elementares no ajuri pressupõe atividades de contraprestação de serviços. Desse modo, as crianças se engajam não apenas no trabalho de subsistência, mas nas redes de relações sociais da família extensa.

Crianças e jovens participam no trabalho da produção da farinha, nas tarefas de descascar e peneirar a mandioca. Elas manuseiam facas sob a vigilância de adultos, mas não têm a obrigação de cumprir tarefa ou seguir o ritmo adulto. Na vida diária, no entorno da casa, espera-se também que meninos e meninas cuidem das crianças menores. As crianças de famílias elementares vizinhas organizam-se em grupos de diferentes idades para brincadeiras coletivas, frequentemente sob a supervisão de uma criança mais velha, orientada pelos pais a cuidar dos menores. Essa criança mais velha é reconhecida pela habilidade e responsabilidade que demonstra ter na supervisão dos pequenos.

À medida que vão crescendo, meninos e meninas passam a exercer atividades com maior responsabilidade. As crianças costumam acompanhar as mães que vão à beira do rio lavar louças ou roupas e colaboram nessas atividades. Também auxiliam mães a carregar baldes de água do rio até a casa.

Quando os adultos da família elementar estão envolvidos em atividades fora da casa, as meninas mais velhas assumem a responsabilidade de preparar o almoço. Lisinha (12 anos), por exemplo, cozinhou o almoço para toda a família que estava cuidando da roça, plantando e capinando, na parte da manhã. Por sua vez, os meninos mais velhos frequentemente pescam sozinhos ou com outros meninos quando seus pais estão envolvidos em outras atividades, suprindo toda a família.

Essas atividades são vistas como aquisição de habilidades que não se restringem ao mero aprendizado intelectual paralelo ao crescimento do corpo biológico, mas é um saber prático, no sentido de um aprendizado que literalmente incorpora o saber e expressa uma noção Munduruku de vida saudável. Por isso, essas atividades são valorizadas. Para os Munduruku, o desenvolvimento de determinadas aptidões físicas e sociais não é tido como uma concessão dada por algum processo biológico autômato, mas é resultado de um processo social de investimento pessoal e coletivo sobre o corpo que se fabrica. Na troca de dentição, por exemplo, esperava-se que Poli agisse ativamente. Sua mãe lhe deu um cabo de madeira e, depois, de metal, para ficar mordendo para amolecer e fazer cair o dente, pois dizia que sem isso ele não cairia e ela ficaria com os dentes tortos. As mães costumam passar ninho de beijaflor no seio das meninas, para que fiquem pequenos e não cresçam muito. O menino deve cortar uma 
árvore grossa quando muda de voz, para ter força, ser ativo e disposto, "para não ser preguiçoso", quando for adulto, conforme explicou Iara, após comentar com a nora que seu filho já podia se preparar. Anos mais tarde, quando reencontramos esse menino, que ouvia a mãe e a tia comentarem sobre o que ele teve que fazer "para não ser preguiçoso", ele confirmou que cortou um babaçuzeiro. Essas práticas são consideradas importantes para a saúde da pessoa, sendo frequentemente evocadas como causa da longevidade dos anciãos 24 .

\section{Promoção à saúde indígena e conflitos com o modelo médico hegemônico}

A análise etnográfica demostra que as práticas de autoatenção são prioritárias e centrais para a reprodução biossocial dos Munduruku. Entretanto, como destaca Langdon 4, esses saberes dificilmente são encarados como relevantes pelos profissionais de saúde no cotidiano da atenção biomédica.

A EMSI comporta a atuação de diferentes profissionais com escolaridade e formação variada 19. Embora os profissionais de saúde encerrem uma pluralidade de pontos de vista, valores e ideais que refletem a singularidade das experiências vividas, tanto pessoais, quanto de formação acadêmica, a atuação na saúde indígena, com frequência, evoca tradições sanitaristas, demandas e significados próprios de uma ordem relativamente estranha ao cotidiano das populações indígenas.

Ainda que a atitude cotidiana de profissionais de saúde não seja homogênea na relação com a alteridade representada pelos indígenas, a própria organização dos serviços, hierarquias, práticas burocráticas e deficiências estruturais e operacionais favorece conflitos, distorções, falhas, negações com prejuízo ao ideal da "atenção diferenciada", conforme idealizado na Política Nacional de Atenção à Saúde do Povos Indígenas (PNASPI) 37.

Ironicamente, é a execução das políticas públicas e em nome da promoção da saúde que se reproduz o "habitus higienista", pautado pela lógica tutelar do Estado sobre as populações indígenas. A lógica tutelar ressurge ao "desautorizar" as práticas indígenas, na busca por uma promoção da saúde etnocêntrica e civilizatória, com uma "frequente desconsideração por outras formas de higiene e cuidados em saúde" 38 (p. 193). Essa lógica tutelar, higienista, benevolente e indiferente reproduz relações assimétricas entre profissionais de saúde e indígenas, por meio da construção de estereótipos que justificam as dificuldades, os improvisos e as falhas da atenção e do modelo de gestão dos serviços oficiais de saúde 24,38.

\section{Considerações finais}

Os Munduruku compartilham um modelo de como o corpo se insere no cosmo que difere do modelo biomédico, marcado pelo individualismo materialista e pela prioridade da fisiologia e biologia sobre o meio social e ambiental. Para os Munduruku, o corpo é construído socialmente, isto é, fabricado na medida em que saúde e bem-estar físico apresentam-se como força, disposição e autonomia para colaborar nas atividades da vida cotidiana, na incorporação de habilidades sociais. Essas habilidades, por sua vez, são compreendidas como demarcadoras das etapas do fluxo de vida. As práticas de autoatenção Munduruku visam à promoção da saúde da coletividade, sendo o corpo individual, antes de tudo, um produto social em conexão com o cosmo, semelhante a outros povos indígenas 14,15,16,17,20, $21,22,23,27,28,33,34,35,36,39$

As práticas de autoatenção à menstruação entre os Munduruku são realizadas no âmbito da família elementar, a fim de prevenir enfermidades e morte. Os saberes e práticas relativos à autoatenção à menstruação emergem por meio de experiências coletivas repassadas entre gerações de mulheres. Segundo os Munduruku, cumprir as prescrições e restrições associadas à menstruação é parte do processo de fabricação do corpo e da pessoa. Assim, valorizam-se os laços sociais e a participação no universo de relações cosmológicas. Isso difere da noção biomédica de corpo excessivamente reducionista, que desponta como obstáculo à promoção da atenção diferenciada, conforme preconizado pela PNASPI 4,5,6,7,8,9,18,26,38,39.

A necessidade de se buscar o ideal da "atenção diferenciada", conforme requer a PNASPI 37, pressupõe reconhecimento, por parte de profissionais e gestores, da importância das práticas de autoatenção para as populações locais. Esse reconhecimento também contribui para maior sensibilidade 
e competência em promover relações interétnicas menos assimétricas e mais dialógicas, objetivando "desenvolver uma atitude crítica e reflexiva sobre suas próprias práticas" 5 (p. 46).

Neste artigo, demonstramos que o ideal de qualidade de vida é buscado no processo de autoatenção por meio de uma diversidade de práticas que se iniciam na gestação e seguem ao longo da vida. Esse processo é percebido pelos Munduruku como eficaz na reprodução biossocial da coletividade, como processo contínuo de construção dos corpos e promoção da saúde.

\section{Colaboradores}

R. P. Dias-Scopel contribuiu na concepção e coordenação do projeto, na pesquisa de campo, na análise e interpretação dos dados, na redação e revisão crítica relevante do conteúdo intelectual. D. Scopel contribuiu na pesquisa de campo, na análise e interpretação dos dados, na redação e revisão crítica relevante do conteúdo intelectual.

\section{Informações adicionais}

ORCID: Raquel Paiva Dias-Scopel (0000-00029579-475X); Daniel Scopel (0000-0001-70745241).

\section{Agradecimentos}

Agradecemos aos Munduruku da Terra Indígena Kwatá-Laranjal, pela colaboração e pelo apoio na realização da pesquisa. D. Scopel agradece ao Conselho Nacional de Desevolvimento Científico e Tecnológico $(\mathrm{CNPq}) /$ Fundação de Amparo à Pesquisa do Estado do Amazonas (FAPEAM) e ao Instituto Leônidas e Maria Deane/Fundação Oswaldo Cruz, pela bolsa DCR.

\section{Referências}

1. Young A. Some implications of medical beliefs and practices for social anthropology. Am Anthropol 1976; 78:5-24.

2. Menéndez EL. Sujeitos, saberes e estruturas: uma introdução ao enfoque relacional no estudo da saúde coletiva. São Paulo: Editora Hucitec; 2009.

3. Menéndez EL. Autoatención de los padecimientos y algunos imaginarios antropológicos. Desacatos 2018; 16:104-13.

4. Langdon EJ. Salud indígena en Brasil: pluralismo médico y autoatención. Desacatos 2018; 16:8-15.

5. Langdon EJ. Uma avaliação crítica da atenção diferenciada e a colaboração entre antropologia e profissionais de saúde. In: Langdon EJ, Garnelo L, organizadores. Saúde dos povos indígenas: reflexões sobre antropologia participativa. Rio de Janeiro: Contra Capa; 2004. p. 29-45.

6. Cardoso MD. Saúde e povos indígenas no Brasil: notas sobre alguns temas equívocos na política atual. Cad Saúde Pública 2014; 30:860-6.

7. Langdon EJ, Garnelo L. Articulación entre servicios de salud y "medicina indígena": reflexiones antropológicas sobre política y realidad en Brasil. Salud Colect 2017; 13:457-70.

8. Langdon EJ, Garnelo L, organizadoras. Saúde dos povos indígenas: reflexões sobre antropologia participativa. Rio de Janeiro: Contra Capa; 2004.

9. Scopel D, Dias-Scopel RP, Langdon EJ. A cosmografia Munduruku em movimento: saúde, território e estratégias de sobrevivência na Amazônia Brasileira. Boletim do Museu Paraense Emílio Goeldi. Ciências Humanas 2018; 13:89-108.

10. Cardoso YC. O currículo de linguagens na educação escolar munduruku: estratégias de planejamento. Revista Amazônida 2017; 2:4-30.

11. Amoroso M. O nascimento da aldeia Mura: sentidos e modos de habitar a beira. In: Amoroso M, Santos GM, organizadores. Paisagens ameríndias: lugares, circuitos e modos de vida na Amazônia. São Paulo: Terceiro Nome; 2013. p. 93-114. 
12. Murphy RF. Headhunter's heritage. Berkeley: University of California Press; 1960.

13. Melatti JC. Ritos de uma tribo Timbira. São Paulo: Ática; 1978.

14. Viegas SM. Eating with your favourite mother: time and sociality in a Brazilian Amerindian Community. J R Anthropol Inst 2003; 9:21-37.

15. Gow P. The perverse child: desire in a native Amazonian subsistence economy. Man 1989; 24:567-82.

16. Tassinari AMI. Concepções indígenas de infância no Brasil. Tellus 2007; 7:11-25.

17. Rosengren D. Corporeidade Matsigenka: uma realidade não biológica sobre noções de consciência e a constituição da identidade. Rev Antropol (São Paulo) 2006; 49:133-63.

18. Scopel D, Dias-Scopel RP, Wiik FB. Cosmologia e intermedicalidade: o campo religioso e a autoatenção às enfermidades entre os índios Munduruku do Amazonas, Brasil. Tempus (Brasília) 2012; 6:173-90.

19. Scopel D, Dias-Scopel RP, Langdon EJ. Intermedicalidade e protagonismo: a atuação dos agentes indígenas de saúde Munduruku da Terra Indígena Kwatá-Laranjal, Amazonas, Brasil. Cad Saúde Pública 2015; 31:2559-68.

20. Langdon EJ. When tapir is an anaconda: women and power among the Siona. Latin American Indian Literatures Journal 1991; 7:7-19.

21. Conklin B, Morgan LM. Babies, bodies, and the production of personhood in North America and a native Amazonian society. Ethos 1996; 24:657-94.

22. Belaunde LE. El recuerdo de luna: género, sangre y memoria entre los pueblos amazónicos. Lima: Fondo Editorial de la Facultad de Ciencias Sociales; 2005.

23. Overing J. O fétido odor da morte e os aromas da vida: poética dos saberes e processo sensorial entre os Piaroa da bacia do Orinoco. Rev Antropol (São Paulo) 2006; 49:19-54.

24. Dias-Scopel RP. A cosmopolítica da gestação, do parto e do pós-parto: práticas de autoatenção e o processo de medicalização entre os índios Munduruku. Brasília: Paralelo 15; 2015.

25. Dias-Scopel RP, Scopel D, Langdon EJ. Gestação, parto e pós-parto entre os Munduruku do Amazonas: confrontos e articulações entre o modelo médico hegemônico e práticas indígenas de autoatenção. Ilha Revista de Antropologia 2017; 19:183-216.

26. Dias-Scopel RP, Scopel D. ¿Quiénes son las parteras munduruku? Pluralismo médico y autoatención en el parto domiciliario entre indígenas en Amazonas, Brasil. Desacatos 2018; 16:16-33.
27. Murphy RF. Mundurucú religion. Berkeley: University of California Press; 1958.

28. Tempesta GA. Travessia de Banzeiros: historicidade e organização sociopolítica apiaká [Tese de Doutorado]. Brasília: Universidade de Brasília; 2009.

29. Harris M. People of the Amazon floodplain: kinship, work and sharing in a caboclo community near Óbidos, Pará, Brazil. London: University of London; 1996.

30. Maués RH. Padres, pajés, santos e festas: catolicismo popular e controle eclesiástico: um estudo antropológico numa área do interior da Amazônia. Belém: Editora Cejup; 1995.

31. Slater C. Dance of the dolphin: transformation and disenchantment in the Amazonian Imagination. Chicago: University of Chicago Press; 1994.

32. Wawzyniak J. "Engerar": uma categoria cosmológica sobre pessoa, saúde e corpo. Ilha Revista de Antropologia 2010; 5:33-55

33. Langdon EJ. A doença como experiência: construção da doença e seu desafio para a prática médica. Florianópolis: Programa de Pós-graduação em Antropologia Social, Universidade Federal de Santa Catarina; 1995. (Antropologia em Primeira Mão, 12).

34. McCallum C. Gender and sociality in Amazonia: how real people are made. Oxford: Berg; 2001.

35. Overing J. Elogio do cotidiano: a confiança e a arte da vida social em uma comunidade amazônica. Mana 1999; 5:81-10.

36. Conklin B. Reflections on Amazonian anthropologies of the body. Med Anthropol Q 1996; 10:373-5.

37. Fundação Nacional de Saúde. Política Nacional de Atenção à Saúde dos Povos Indígenas. Brasília: Fundação Nacional de Saúde; 2002.

38. Dias da Silva C. De improviso e cuidados: a saúde indígena e o campo da enfermagem. In: Teixeira CC, Garnelo L, organizadoras. Saúde indígena em perspectiva: explorando suas matrizes históricas e ideológicas. Rio Janeiro: Editora Fiocruz; 2014. p. 181-212.

39. Coimbra Jr. CEA, Garnelo L. Questões de saúde reprodutiva da mulher indígena no Brasil. In: Monteiro S, Sansone L, organizadores. Etnicidade na América Latina: um debate sobre raça, saúde e direitos reprodutivos. Rio de Janeiro: Editora Fiocruz; 2004. p. 153-74. 


\section{Abstract}

Longevity, health, and collective and individual well-being are among the socially shared expectations of the Munduruku people who live on the Kwatá-Laranjal Indian Reservation in Amazonas State, Brazil. Daily life in a cosmos full of beings is surrounded by dangers that threaten these expectations, and whose agencies can result in disease and death. Based on ethnography, through participant observation and narratives, we analyze the self-care practices dedicated to the construction of the Munduruku woman's body, valuing the perspectives and active role of "lay" persons in this process. These practices begin in pregnancy and extend throughout life in an ongoing process of construction of the body, maintenance of health, and acquisition of skills, marked by interaction between persons of different ages. The focus of Munduruku practices is not the body in the sense determined by the biomedical paradigm, but its participation as a person in social and cosmological relations, through experiences that link body, health, and environment. The Munduruku perspective on this process displays radical differences in relation to modern individualism and the biomedical notion of the body, excessively reductionist. An understanding of the indigenous perspective can help promote improvements in the quality of differentiated care, as recommended by the Brazilian National Healthcare Policy for Indigenous Peoples.

Health of Indigenous Peoples; South American Indians; Medical Anthropology; Women's Health

\section{Resumen}

La longevidad, la salud y el bienestar colectivo e individual figuran entre las expectativas socialmente compartidas por los Munduruku, que habitan la Tierra Indígena Kwatá-Laranjal, en el Amazonas, Brasil. El quehacer de la vida diaria, en un cosmos lleno de seres, está rodeado de peligros que amenazan las expectativas mencionadas anteriormente, cuyas vicisitudes pueden resultar en enfermedad y muerte. A partir de la etnografía, realizada mediante observación participante y narraciones, analizamos las prácticas de autoatención, dirigidas a la construcción del cuerpo de la mujer Munduruku, valorando tanto la perspectiva, como el papel activo de las personas "no especialistas" en este proceso. Estas prácticas se inician en la gestación y se extienden a lo largo de la vida, en un proceso continuo de construcción del cuerpo, mantenimiento de la salud y adquisición de habilidades, marcado por la interacción entre personas de diferentes edades. El foco de las prácticas de atención Munduruku no es el cuerpo, tal y como lo entiende el paradigma biomédico, sino la participación de este, como persona, en las relaciones sociales y cosmológicas, mediante experiencias que articulan cuerpo, salud y ambiente. La perspectiva Munduruku sobre este proceso presenta diferencias radicales, respecto al individualismo moderno y la noción biomédica de cuerpo, excesivamente reduccionista. La comprensión de la perspectiva indígena contribuye a promover mejorías en la calidad de la atención diferenciada, conforme lo preconizado por la Politica Nacional de Atención de la Salud de los Pueblos Indígenas.

Salud de Poblaciones Indígenas; Indios

Sudamericanos; Antropología Médica;

Salud de la Mujer
Recebido em 30/Abr/2018

Versão final reapresentada em 31/Out/2018

Aprovado em 09/Nov/2018 